\title{
Significance and Epidemiological Aspects of Late-Season Infections in the Management of Potato Zebra Chip
}

\author{
C. M. Rush, F. Workneh, and A. Rashed
}

First and second authors, Texas A\&M AgriLife Research, Bushland, TX 79012; and third author: University of Idaho, Aberdeen Research and Extension Center, Aberdeen, ID 83210. Accepted for publication 15 April 2015.

\begin{abstract}
Rush, C. M., Workneh, F., and Rashed, A. 2015. Significance and epidemiological aspects of late-season infections in the management of potato zebra chip. Phytopathology 105:929-936.

Zebra chip (ZC) of potato is putatively caused by the fastidious, phloem-limited bacterium 'Candidatus Liberibacter solanacearum' (Lso), which is transmitted by the potato psyllid (Bactericera cockerelli). The disease, which significantly impacts both crop yield and quality, was first identified in the United States from south Texas in 2000. It reached epidemic levels in north Texas and certain production areas in Colorado, Nebraska, and New Mexico from 2004 to 2007 and it caused severe losses in fields in Oregon, Washington, and Idaho in 2011. The potato plant is susceptible to infection at all developmental stages, but disease management programs have focused on vector control through early and repeated insecticide applications, in an effort to minimize early to

midseason infections which are most damaging. Growers often terminate spray programs 2 to 3 weeks prior to crop harvest due to lack of visible treatment effects on crop yield or quality. However, recent studies on vector transmission and host-pathogen interactions have revealed that late-season infections pose a significant, previously unrecognized, threat to crop quality. The pathogen can move from an infected leaf to tubers within 2 days; however, tubers infected less than 1 week before harvest will remain asymptomatic and the pathogen will be undetectable. When these tubers are placed into storage they are assumed to be disease free. However, Lso can continue to multiply in respiring tubers during storage, resulting in reduced tuber quality. Likewise, if plants become infected a few days before vines are killed, ZC can continue to develop in infected tubers before they are harvested. Perspectives on the significance of lateseason infections and some of the more important issues associated with those infections are discussed.
\end{abstract}

In 2000, a new disease of potatoes called zebra chip (ZC) was first reported in the United States from a commercial potato field near Weslaco, TX, in the lower Rio Grande Valley. The disease had been economically important since the mid-1990s in the Mexican states of Coahuila and Nuevo Leon in northeastern Mexico, which border the winter potato production area in Texas where ZC was first found. By 2004 and 2005, ZC had spread from the lower Rio Grande Valley to west Texas and the Texas High Plains, where it reached epidemic levels and was responsible for millions of dollars in losses to producers and processors (Rosson 2006; Goolsby et al. 2007). Initially, the disease didn't garner much concern outside of Texas, but by 2008 the disease had spread to California, Colorado, Kansas, Nebraska, New Mexico, and Wyoming (Wen et. al. 2009). In 2011, $\mathrm{ZC}$ was reported for the first time, and caused widespread damage in the Pacific Northwest states of Washington, Oregon, and Idaho, which account for nearly 60 percent of all U.S. potato production. The disease also has been reported recently from several countries in Central America and New Zealand (Lin and Gudmestad 2013).

$\mathrm{ZC}$ is putatively caused by the fastidious, phloem-limited bacterium, 'Candidatus Liberibacter solanacearum' (Lso), which is transmitted by the potato psyllid (Bactericera cockerelli) (Liefting et al. 2009a, 2009b; Munyaneza et al. 2007a, 2007b). The disease was named for the characteristic striping and discoloration in potato chips produced from infected tubers, but it affects all market classes of potato by reducing both yield and quality (Munyaneza 2012). Lso-infected plants exhibit a range of foliar symptoms that include leaf purpling, chlorosis and curling, aerial tuber production and eventual necrosis, vine collapse, and plant death (Fig. 1). Tuber symptoms include rotted stolons,

Corresponding author: C. M. Rush; E-mail address: crush@ag.tamu.edu discoloration of the vascular ring, and necrotic flecking or streaking of the medullary rays (Fig. 1). Although eating infected potatoes is not harmful to humans or livestock, fried products exhibit defects, which render them unmarketable.

Typically, infected symptomatic plants first appear after flowering, and initially there is a definite edge effect, with greater disease incidence on the edges than the interior of fields (Workneh, et al. 2012). In the absence of adequate vector control, psyllids populations increase rapidly, resulting in widespread disease incidence across fields, but even in well-managed fields clusters of diseased plants may develop randomly. Plants infected early in the season exhibit the most severe symptom expression and yield reductions and often die. However, plants infected late in the season may be asymptomatic and even test negative for Lso, thereby resulting in a significant underestimation of disease incidence. Although early infections are clearly the most damaging, with regard to both yield and quality reductions (Rashed et al. 2014b), it is late-season infections that are most problematic, with regard to disease management, detection, postharvest storage, seed production, and export. Therefore, our objective in this article is to provide our perspective on the significance of late-season infections, highlight some of the issues relating to late-season infections, and offer suggestions for future study.

\section{WHERE DO PSYLLIDS COME FROM AND WHY IS THAT IMPORTANT?}

Even before it was identified as the vector of Lso and associated with $\mathrm{ZC}$, the potato psyllid was recognized as an important pest of potato, which caused the disease psyllid yellows (Wallis, 1955). Early ecological studies reported that the potato psyllid overwintered in northern Mexico and the southwestern United States, from the Trans Pecos region in west Texas to California, and as far 
north as northern New Mexico (Wallis, 1946). Once the potato psyllid was associated with ZC, researchers began intensive surveys to monitor populations in major potato production regions across the western United States. In the Lower Rio Grande Valley of Texas, where ZC was first identified, potatoes are grown as a winter crop and are planted in late December to mid-January and harvested in May. In this region, psyllids are present throughout the year, but populations usually began to increase as temperatures rise in March to April (Fig. 2A). The optimum temperature for psyllid reproduction is around $27^{\circ} \mathrm{C}$ (List, 1939) and little or no adults develop at $32^{\circ} \mathrm{C}$ (Fig. 3; Workneh et al. 2011a, b). As daily maximum air temperatures begin to increase above $32^{\circ} \mathrm{C}$, psyllid populations in the Lower Rio Grande Valley greatly decrease, and by harvest in early May are often undetectable. Conversely, in Washington State and much of the Pacific Northwest (PNW) production region, the majority of potatoes are planted in March and harvested in September and October. In the early part of the season when temperatures are cool, psyllid populations, based on adults captured on sticky traps, are extremely low. However, as temperatures warm, populations rapidly increase and reach a maximum near harvest time (Fig. 2B). This trend of psyllid populations peaking in March to April in south Texas, and progressively later in more northern regions, led to general acceptance of the long-held hypothesis that potato psyllids migrated each year from northern Mexico to the PNW. Farmers developed management practices based on timing of peak populations and developmental stage of the potato crop. Growers in south Texas heavily focused on early season control, growers in north Texas delayed planting in hopes of avoiding peak populations, and many in the PNW, before the 2011 epidemic, chose not to treat at all in the belief that psyllids arriving late in the season posed no threat to their crops. Unfortunately, this belief proved to be incorrect and further studies raised questions as to the validity of the migration hypothesis.

The early belief that psyllids were migrating from south to north during the spring was primarily based on their year-round presence in the southernmost production regions, their progressive appearance, from south to north, in grower's fields during the summer months and lack of evidence for their survival in the northern regions during the winter (Pletsch 1947; Romney 1939; Wallis
1946, 1955). This belief was further supported by the report that psyllids were caught in the atmosphere at altitudes above $1,200 \mathrm{~m}$ (Glick 1939), which suggested that psyllids could well be migrating long distances on air currents. With this mind set, the obvious question following the $2011 \mathrm{ZC}$ epidemic in the PNW (Crosslin et al. 2012a, 2012b; Hamm et al. 2011) was whether the psyllids

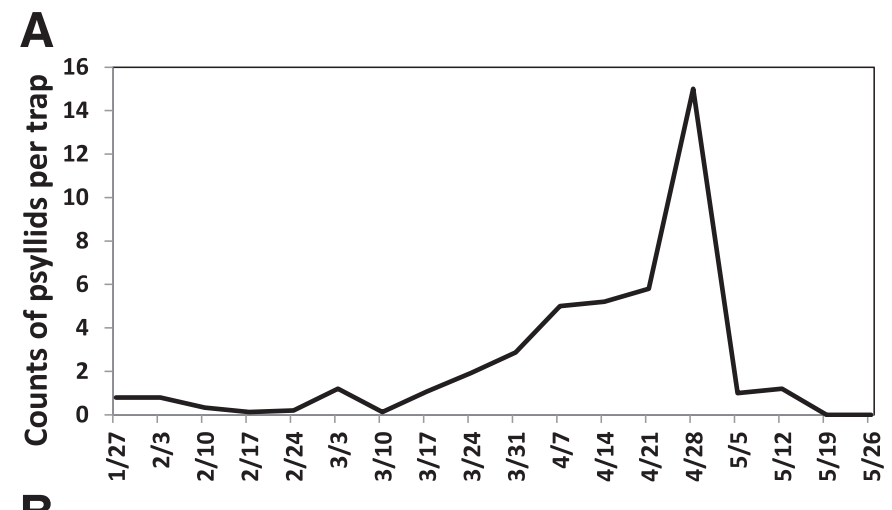

B

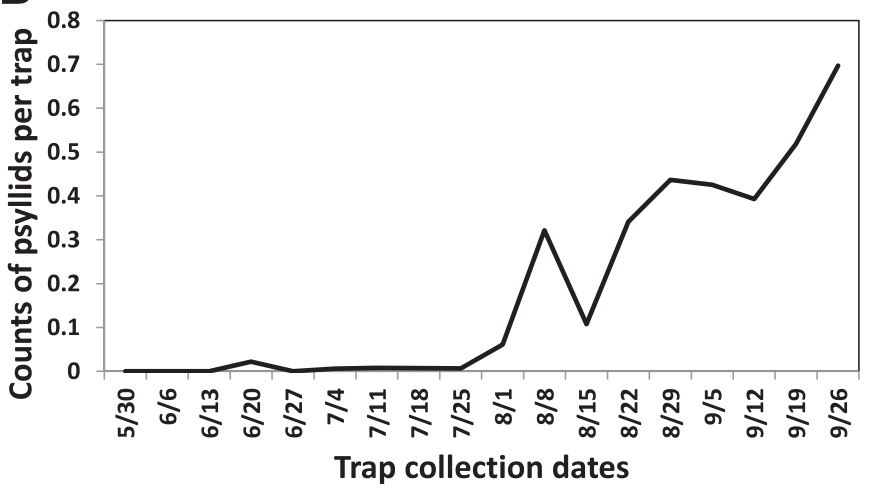

Fig. 2. Seasonal counts of potato psyllids per trap A, in the Rio Grande Valley of Texas and $\mathbf{B}$, in the Pacific Northwest (courtesy of Carrie Wohleb, Washington State University).
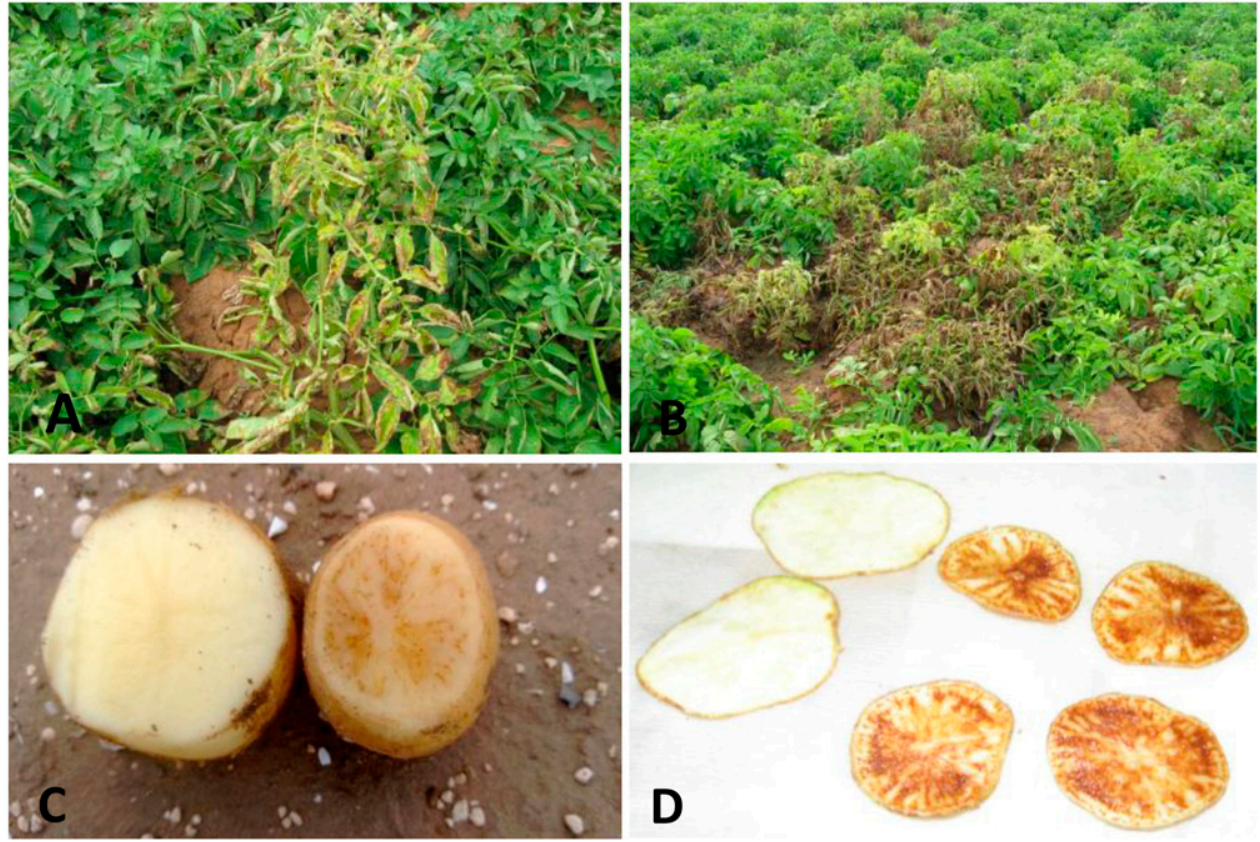

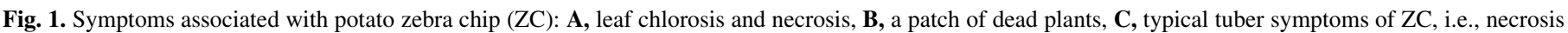

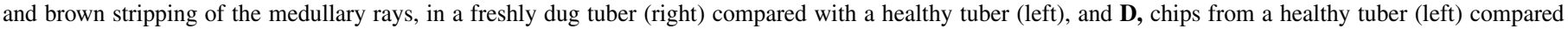
with those from a tuber with ZC (right). Figures A and D were reproduced from Workneh et al. (2012). 
responsible for the disease outbreak originated from south Texas, a known overwintering ground for the vector and the primary focus region for ZC. To address that question, air parcel trajectory analysis was conducted using the HYSPLIT (Hybrid Single Particle Lagrangian Integrated Trajectory) model, developed by the National Oceanic and Atmospheric Administration (Draxler and Hess 1998), on archived data for the 2011 growing season. Backward trajectories from several infected locations in the PNW were generated to identify sources of wind trajectories which may have arrived at those locations during the season. Results of the analyses implicated Arizona and California as possible sources for psyllids, but none of the trajectories during the entire season were found to be associated with Texas (Workneh et al. 2011a). This was not surprising since wind trajectory directions from south Texas generally follow either north or northeast routes, as exemplified by the Puccinia pathway, but seldom cross the Rocky Mountains westward. This was shown to be true in the analysis of forward wind trajectories from the Lower Rio Grande Valley for the second week of May 2011 (Fig. 4, left), the time when psyllids are believed to be leaving the area due to the onset of high temperatures. However,

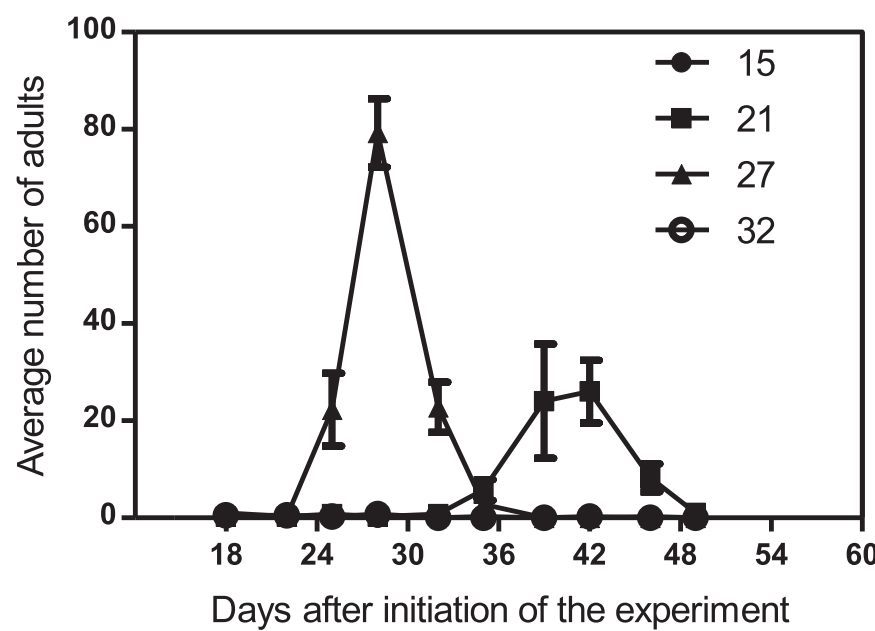

Fig. 3. Effect of various constant temperature levels $\left({ }^{\circ} \mathrm{C}\right)$ on development of adult psyllids. analysis of backward trajectories for the Columbia Basin revealed that there were several instances of wind trajectories originating from southern regions, including Central California, during the growing season (Fig. 4, right).

If psyllids do migrate northward every spring as suggested in early literature, it is possible that the migration takes place as several events, although long-distance transport by air currents in a single event may not be completely ruled out. Psyllids may follow the succession of spring planting or the onset of warmer temperatures as cold winter conditions subside from south to north, resulting in delay in reaching the northern states. This could be one of the main factors why high numbers of psyllids are not usually observed in the PNW states until July (Munyaneza et al. 2009) and was one of the factors which led early investigators to suggest spring migration from winter breeding grounds in the southern regions bordering Mexico (Pletsch 1947; Romney 1939; Wallis 1946; 1955).

Considering the relatively long incubation period of ZC (25 to 30 days), one would think that the late arrival of psyllids in the northern states would result in infection at a later stage of plant development and, thus, result in minimal damage, at least compared with the southern states. However, the 2011 ZC epidemic in the PNW did not follow this assumption, as there was widespread incidence of ZC around the Columbia Basin (Crosslin et al. 2012a, 2012b; Hamm et al. 2011), with some fields being severely affected. Although there were no intensive surveys at the time, the psyllids were estimated to have arrived beginning in mid-June, about a month earlier than their normal appearance (Hamm et al. 2011), but it is unclear whether that factor was responsible for triggering the disease outbreak. Psyllids normally are first detected in the region after mid-July (Munyaneza et al. 2009) and there was no report of their winter survival prior to the 2011 to 2012 winter season, but only after the widespread ZC outbreak in 2011 (Hamm et al. 2011). Thus, at this point, it is difficult to conclude that psyllids responsible for the 2011 epidemic migrated in from long distance or were of local origin. However, it is interesting that the bacteriliferous psyllids collected from infected fields in the Columbia Basin turned out to be the western haplotype (Liu et al. 2006; see below for genetic variations). The western haplotype of the potato psyllid is most prevalent in western Mexico and California, giving some credence to the assumption that the psyllids responsible for the widespread occurrence of ZC in the PNW in 2011 might have migrated from California.
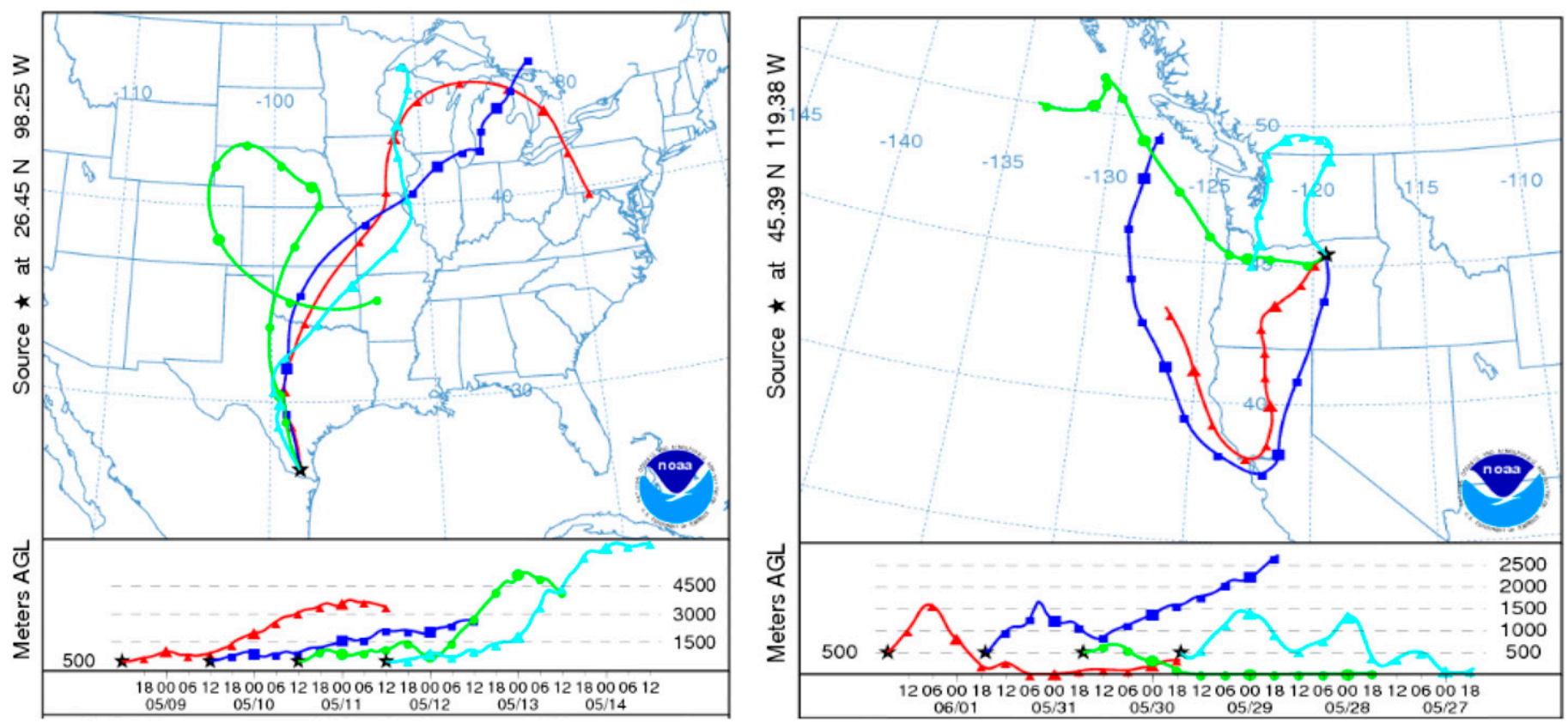

Fig. 4. Forward wind trajectory directions from the Lower Rio Grande Valley of Texas for the second week of May 2011 (left) and backward trajectories from the Columbia Basin of the Pacific Northwest for the week period ending on 1 June 2011 (right). 
Regardless of the psyllid's origin, there was a temperature deviation in 2011 from the previous years that may have accounted for the widespread incidence of $\mathrm{ZC}$. In the PNW, maximum temperatures during the month of June have always been within the favorable range for psyllid reproduction, since the year 2000 when ZC was first detected in the United States (Fig. 5, top). Conversely, maximum temperatures during July historically have been too warm for optimum psyllid reproduction and may have kept psyllid populations low. However, in July 2011, maximum temperatures were much cooler than normal, and well within the range for psyllid reproduction (Fig. 5, bottom), thus possibly accounting for the high psyllid numbers that were recorded that year during midsummer.

Overall, from 2010 to 2014, the proportion of total psyllids captured on sticky traps and testing positive for Lso was less than $3 \%$, although the percentage of Lso-positive psyllids sometimes exceeds this level in individual fields and growing areas (Goolsby et al. 2012; Henne et al. 2013). The highest percentage of Lsopositive psyllids are normally observed in south Texas compared with the northern U.S. regions, an observation supported by the declining trend of ZC incidence across the central United States (Goolsby et al. 2012; Workneh et al. 2013). An obvious question then is do some of the psyllids lose the Lso as they move north, if indeed there is a northward migration? It is difficult to say at this point; however, it has been documented that the fitness of psyllids carrying the bacterium is less than those without (Nachappa et al. 2012) and, thus, it is possible that the number of Lso-positive psyllids may decline. This idea is supported by a recent study by Rush, et al. (2013) in which different densities of psyllids positive

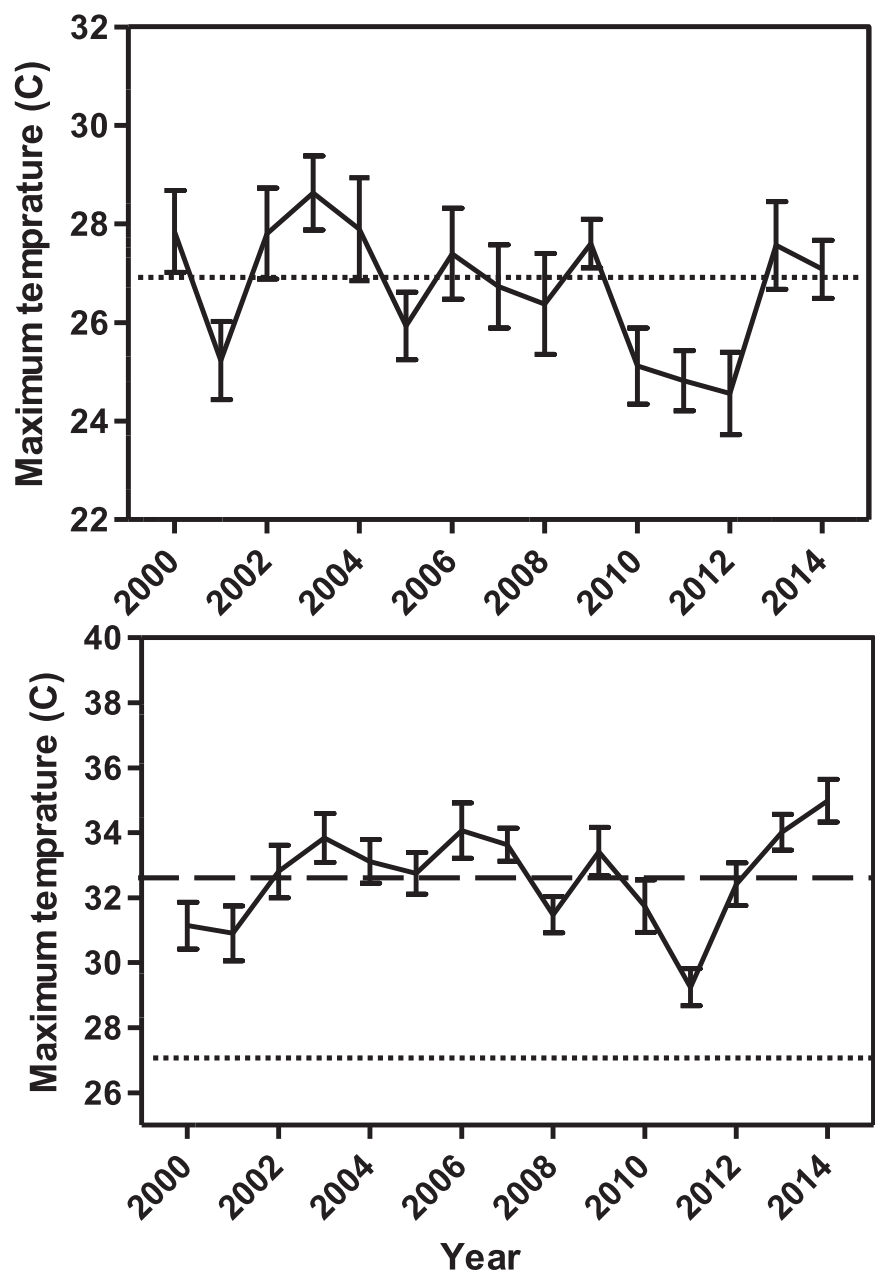

Fig. 5. Monthly average maximum temperature from 2000 to 2014 for June (top) and July (bottom) in Columbia Basin of the Pacific Northwest; dots and broken lines represent optimum and maximum temperature levels, respectively, for psyllid reproduction. for Lso were placed in large cages and allowed to feed undisturbed on potato plants for several months. The percentage of Lso-positive psyllids in the population dropped initially and then began to increase as newly emerged psyllids fed on previously infected plants. However, by the end of the growing season, the percentage of positive psyllids in the population had only reached approximately $40 \%$. In this study, the psyllids were restricted to feed on plants within the cage and the number of Lso-infected plants increased over time, increasing the odds that a feeding psyllid would acquire the pathogen. Such a situation would not be experienced by a migrating population of psyllids and the declining south-north incidence of Lso-positive psyllids is understandable.

Although northward psyllid migrations during the spring may be difficult to unequivocally prove or disprove, the report that potato psyllids overwintered in Idaho following the 2011 epidemic (Murphy et al. 2013) proved that they are capable of surviving the cold winter conditions in the northern states. In addition, studies conducted under controlled conditions, have demonstrated that both adults and nymphs are able to survive for several hours when exposed to subfreezing temperatures (Henne et al. 2010; Whipple et al. 2012), and that psyllids collected from Nebraska exhibited greater cold tolerance than psyllids collected from Texas (Whipple et al. 2012). These studies provided an indication that there may be genetic variability among psyllid populations, with regard to temperature tolerance.

Genetic variability among psyllid populations has been known to exist for nearly a decade. Liu et al. (2006) identified two distinct haplotype clusters of the population based on (among other methods) their intersimple sequence repeats. These haplotypes were designated the western haplotype, which included psyllids from Baja (Mexico) plus areas in southern California, and the central haplotype, covering psyllids from eastern Mexico and the central United States, including Colorado and Nebraska. Recent work by Swisher et al. (2012), using high resolution melting analysis, confirmed this grouping and also identified two additional haplotypes, the northwestern and southwestern. The northwestern haplotype has only been identified in Washington and Idaho, while the southwestern haplotype predominantly has been reported from New Mexico and west Texas. The psyllids overwintering in Idaho and Washington have now been determined to be exclusively of the northwestern haplotype, although their prevalence elsewhere has not been extensively explored.

Although the designations for psyllid haplotypes have been based on the regions from which they were initially identified, there is considerable overlap in their regional distributions (Paetzold et al. 2014; Workneh et al. 2014). In many regions, it appears that time of sampling may be critical as to which of the haplotypes one may encounter. Monitoring of psyllids for a 2-year period in natural vegetation, along the Permian Basin in west Texas and northward to the Texas Panhandle, revealed dramatic shifts in population structure of potato psyllids depending on time of sampling (Paetzold et al. 2014; Workneh et al. 2014). For example, in one of the Permian Basin locations, based on biweekly sample collections, the southwestern haplotype was seldom encountered for most of the year, but between November and January it was the most dominant haplotype of the three haplotypes encountered. A substantial shift in the proportion of haplotypes also was detected in psyllid samples collected from New Mexico potato fields. Initially, the southwestern haplotype was the only type detected in consecutive sample collections from these fields but it later declined dramatically and was overtaken in abundance by the Western haplotype (Workneh et al. 2014).

It appears that the proportion of individual haplotypes composing the psyllid population from a given region is dynamic. Fluctuations in haplotype ratios might occur in response to abiotic environmental variables, development of preferred plant hosts, and/or influxes of new psyllids from regional migrations. The implications of these shifting haplotypes within a regional population, with regard to 
incidence and timing of ZC are highly significant. Recent studies by Paetzold et al. (2014) revealed that the incidence of Lso positive psyllids varies greatly among psyllid haplotypes. Psyllids of the western haplotype exhibited the highest percentage of Lso positive individuals, while none of the southwestern haplotype captured on sticky traps over a 2-year period tested positive for Lso. A similar situation may be occurring annually in the PNW with the resident northwestern haplotype being overwhelmed or displaced by the Western haplotype, which includes a relatively higher percentage of Lso-positive individuals and was implicated with the 2011 ZC epidemic.

It is clear from research conducted over the last few years that psyllid populations can overwinter as far north as potato production regions in the PNW. Furthermore, these populations are genetically and physiologically distinct from populations in the lower Rio Grande Valley of Texas, providing strong evidence against cross country, i.e., Texas to the Canadian border, migration (Swisher et al. 2012). Conversely, it is also clear from psyllid survey trapping data that temporal shifts in predominant psyllid haplotype occur within geographical regions (Paetzold et al. 2014; Workneh et al. 2014). If the resident population possesses a low frequency of Lso positive individuals and is displaced by a high frequency Lso population (whether a different haplotype or the same) the potential for ZC will dramatically increase. However, if the displacing population arrives late in the season, as may be occurring in the PNW, the potential for increased disease risk likely will not be recognized by the average farmer. This is especially true during the last 2 or 3 weeks before harvest, when new infections will remain asymptomatic and titer of Lso will be low and often undetectable.

\section{HOST PATHOGEN INTERACTIONS AND RELEVANCE TO LATE-SEASON INFECTIONS}

Once the potato psyllid was identified as the vector of Lso (Liefting et al. 2009a; Munyaneza et al. 2007a), questions quickly arose concerning the infection process and subsequent disease development. These questions were of immediate concern to producers who needed to rapidly develop effective, economically sustainable disease management programs. In the Lower Rio Grande Valley, potato psyllids are present before emergence but symptoms of ZC always occur post flowering. This observation led some to believe that the potato plant might be less susceptible to infection by Lso before flowering. However, a series of studies demonstrated that the potato plant was susceptible to Lso infection at all stages of development (see below), and that the appearance of $\mathrm{ZC}$ symptoms at, and after, the flowering stage is predicted by the time of infestation by the potato psyllid and the incubation time of ZC.

Potato psyllids can acquire Lso from infected hosts and subsequently inoculate uninfected plants with the pathogen as they feed on phloem sap. While potato psyllids may be initially attracted to infected hosts plants, they show preference to feed on healthy plants once they acquire Lso (Davis et al. 2012), a behavior promoting pathogen spread. Although their long distance movement can facilitate pathogen spread, potato psyllids are also known to be highly efficient in transmitting Lso (Rashed et al. 2012; Munyaneza, 2012). Rashed et al. (2012) showed that the inoculation success of a single psyllid may reach as high as $70 \%$ within $48 \mathrm{~h}$ of exposure to the host plant tissue (see also Buchman et al. 2011, Hansen et al. 2008). Moreover, psyllid numbers can also influence the probability of successful inoculation. For instance, Lso may be transmitted with up to $100 \%$ success when there are multiple infectious psyllids present on the plant (Rashed et al. 2012). Potato psyllids are not only efficient in transmitting Lso, but they can also complete the inoculation process within a short period of time. While it was shown previously that Lso inoculation can be completed within $6 \mathrm{~h}$ (Buchman et al. 2011), a more recent study, using tomato plants, indicated that Lso inoculation process could be completed within $2 \mathrm{~h}$ of psyllid placement on the host plant
(Sandanayaka et al. 2014). The efficiency of the potato psyllids in transmitting Lso, combined with the short inoculation access period needed, render the presence of the infectious potato psyllids a threat until right before harvest. This is of particular importance in the PNW region where infectious psyllid numbers tend to peak later in the season (Fig. 2B), thus increasing the risk of late-season infection. In addition to their efficiency and rapidness in transmitting Lso, the effect of psyllid numbers on the rate of successful transmission events suggest that pesticide applications need to possess quick knock-down and/or feeding inhibition effects to be effective in minimizing Lso spread and transmission. Current disease management programs for early and midseason control of $\mathrm{ZC}$ that rely on frequent insecticide applications have been quite effective in reducing the impact of $\mathrm{ZC}$ on potato production. However, evaluating the effectiveness and economic justification of foliar sprays in managing ZC toward the end of the season relies on a detailed understanding of Lso-plant interaction in the field and even postharvest.

A field study was initiated to investigate the relationship between plant developmental stage at time of infection and subsequent ZC symptom development in foliage and tubers. Results from this 2-year investigation, and follow-up studies, shed light on previously unknown aspects of Lso-plant interactions, and highlighted the need for vector management until harvest (Rashed et al. 2013; Rashed et al. 2014b, 2015). Experimental plants were infested with bacteriliferous psyllids weekly, beginning 1 week after emergence and continuing until a week before harvest. Following infestations, psyllids were allowed to feed on infested plants for 1 week and then removed with insecticides. At harvest, 9 weeks after the initial infestation, tubers were visually scored for severity of ZC symptoms and tested by qPCR for Lso. Foliar symptoms first appeared 3 to 4 weeks after infestation and disease progress and pathogen titer increase were uniform among all infestation dates, clearly indicating that preflowering plants were not resistant to infection or disease development. Plants infested 5 to 9 weeks before harvest exhibited severe foliar symptoms, but those infested less than 3 weeks before harvest exhibited no foliar symptoms. However, $31 \%$ of the tubers from plants infested 3 weeks before harvest exhibited typical symptoms of ZC. This was significant because it demonstrated that symptoms of ZC develop earlier in tubers following infestation than in foliage. The vast majority of tubers from plants infested $>3$ weeks before harvest exhibited severe symptoms of ZC, and tuber yield was significantly reduced in plants infested greater than weeks before harvest, with the greatest reduction in the earliest three infestation dates (i.e., the three longest infection durations). Only $1.3 \%$ of tubers from plants infested 2 weeks before harvest exhibited symptoms of ZC, however $74 \%$ of the tubers tested positive for Lso. This demonstrated that although these late-season infections, i.e., 2 weeks before harvest, had no impact on tuber yield and no symptoms of ZC were visible, tubers were infected by Lso and processing quality was diminished. However, in the latest treatment, i.e., plants infested 1 week before harvest, no disease symptoms or Lso was detected in tubers.

In a follow-up study (Rashed et al. 2015), tubers harvested from the various infestation treatments were placed in cold storage for several months. One question raised was whether emergence success of seed tubers is affected by the severity of symptoms and/or the time of infection? To address this question, the tubers were removed from the cold storage and planted to determine whether the length of time that they had been infected before harvest would impact seedling emergence. The expectation was that tubers infected late in the season, with minimal or no symptoms of $\mathrm{ZC}$, would exhibit higher seedling emergence than those that were infected earlier in the season and exhibited severe symptoms of ZC. Interestingly, symptom severity was not correlated to seedling emergence and even tubers with very mild symptoms of $\mathrm{ZC}$ had very low percentages of seedling emergence. Even Lso-infected, 
asymptomatic tubers from plants infested only 2 weeks before harvest exhibited poor seedling emergence. However, the most unexpected result from this study was that asymptomatic tubers, infested only a week before harvest, and testing negative for Lso, also had significantly reduced seedling emergence when compared with tubers from healthy, noninfested control plants. This result suggested that the tubers were infected by Lso, but at nondetectable levels, and that perhaps tuber physiology had been already affected in response to psyllid infestation and/or Lso infection. Whether the reduced emergence success results from host response to Lso, or a combination of Lso and psyllid feeding, remains to be addressed. Although 'psyllid yellows', the condition associated with direct potato psyllid feeding, does not cause tuber necrosis (Secor et al. 2009), it can induce reduced germination success of seed tuber (Snyder et al. 1946). In Rashed et al. (2015) psyllids used for Lso inoculations were removed after 1 week of inoculation access period and since plants are generally expected to recover from psyllid yellows once psyllids are removed (Sengoda et al. 2013), the effect of insect feeding per se on seed germination was expected to be minimal.

Zebra chip is known to interfere with carbohydrate metabolism (Gao et al. 2009), amino acid composition (Yang et al. 2011; Wallis et al. 2012) and phenolic contents (Navarre et al. 2009; Wallis et al. 2012) within tuber tissue. The overall effect of ZC on plant biochemical composition was confirmed in subsequent studies (Rashed et al. 2013; Wallis et al. 2015), however, there were also differences in outcome among the different studies. Such differences reflect the significant role of environmental variables on the outcome of complex Lso-tuber interactions. Prominent, examples of differences in responses to $\mathrm{ZC}$ were those of individual amino acids. The most common response found across the majority of studies was that ZC symptoms in tubers are associated with elevated levels of reducing sugars and phenolics. Increased concentration of phenolics is responsible for enzymatic browning of the infected tubers (e.g., elevated polyphenol and peroxidase activity levels) (Wallis et al. 2012; Rashed et al. 2013). Some phenolic compounds are also known to be associated with reduced seed-tuber germination (Williams and Hoagland 1982). In relation to this, Rashed et al. (2013) documented an increased polyphenol activity in tubers from plants, which were infected as late as one week before harvest but whose tubers tested negative for Lso at harvest (Rashed et al. 2013). This increased level of polyphenol oxidase activity soon after Lso infection, at least in part, may explain the reduced emergence success of late-season infected tubers (Rashed et al. 2015).

\section{PRE- AND POSTHARVEST MANAGEMENT ISSUES IN RELATION TO LATE-SEASON INFECTIONS}

Potato psyllid efficiency in transmitting Lso and their ability to inoculate plants in a short time period, in conjunction with rapid systemic spread of the pathogen and almost immediate impact on tuber quality, highlights the potential significance of late-season infections and the importance of managing vector numbers until vine-kill, or in the absence of vine kill, until harvest. This is of particular importance in areas, such as the PNW, where vector numbers tend to peak toward the end of the season and the vast majority of the crop is placed into storage. Even when a grower has successfully managed pests and disease throughout the season, failure to maintain vigilance at the end of the season and during storage could prove disastrous. It is important that growers have a basic understanding of host-pathogen interactions and the conditions that favor disease development, both pre and postharvest, and to devise an overall "planting to processing" disease management strategy based on this information (Box 1).

In many production areas before potatoes are harvested, above ground foliage and vines are killed and tubers are left in the ground for up to a month to allow skins to set, thereby reducing the likelihood of bruising and rot during harvest and storage, respectively. If bacteriliferous psyllids infest the crop just days before vine kill and plants become infected, the potential exists for ZC to develop in tubers before they are harvested, especially when temperatures are warm. In a preliminary study, Rush et al. (2014) infested potatoes with bacteriliferous psyllids 2 or 7 days before and after vine-kill and potatoes were harvested a month later. During this preharvest period, $10 \mathrm{~cm}$ soil temperatures ranged from approximately 23 to $27^{\circ} \mathrm{C}$. At harvest, tubers were visually rated for symptoms of ZC and tissue samples were collected to test for Lso. No tubers from plants infested after vine-kill tested positive for Lso or exhibited any symptoms of ZC, but $85 \%$ of tubers from plants infested 7 days before vine-kill exhibited moderate to severe symptoms of ZC and tested positive for Lso. Surprisingly, 47\% of the tubers from plants infested just two days before vine-kill also exhibited symptoms of ZC. Those tubers tested positive for Lso and produced dark, discolored chips when fried. This result demonstrated the rapidity with which Lso moves from infected leaf to tuber, and highlighted the difficult decisions faced by farmers with regard to vector control and late-season disease management. It also raised questions concerning the potential for continued disease development during storage.

Potatoes destined for long term commercial storage typically are dug when pulp temperatures are between 12 and $20^{\circ} \mathrm{C}$. These temperatures, which are conducive for multiplication of Lso and subsequent disease development, are much warmer than the desired storage temperature, which varies for different cultivars but usually is in the range of 5 to $7^{\circ} \mathrm{C}$. After harvest, potatoes are cooled down to $13^{\circ} \mathrm{C}$ as quickly as possible, but depending on the starting temperature this "curing" stage may take several weeks. After the curing stage, temperatures are ramped down approximately $0.3^{\circ} \mathrm{C}$ each day until they reach the desired set point. Because the transition period from harvest to storage set point takes several weeks and tuber temperatures during this time are typically conducive for Lso multiplication, the potential for disease development in storage is significant. This was verified in studies by Rashed et al. (2014a) in which tubers from plants infested with bacteriliferous psyllids, either 10 or 4 days before harvest, were placed into commercial storage conditions. At harvest, all tubers from the 4 day treatment, and $95 \%$ of those from the 10 day treatment, tested negative for Lso and symptoms of ZC were absent. However, after the 3 -week curing period, approximately $30 \%$ of the tubers from the 10 day treatment tested positive for Lso and by the end of the study $40 \%$ of the tubers from the 4 day treatment tested positive for Lso, verifying again that Lso rapidly moves from infected leaves to the tuber and continues to replicate in respiring tubers during storage. With late-season infestations of bacteriliferous potato psyllids, there is no guarantee that tubers that go into storage with no indication of ZC or infection by Lso will come out of storage in the same condition. This situation causes a plethora of complications for the potato industry but especially for seed producers,

\section{BOX 1}

Factors impacting the occurrence and significance of late-season infections

- End of season environmental conditions conducive for vector, pathogen transmission, and disease development

- Physiological condition of host plants and attraction to vector

- Number of Lso-positive psyllids present in the field

- Application and effectiveness of late-season management practices

- Intended end use of crop 
storage facilities and processors who depend on stored potatoes for a continuous, year-round supply of high quality product.

\section{LATE-SEASON INFECTIONS, AN EMERGING ISSUE FOR AN EMERGING DISEASE}

When ZC was first detected in Texas in 2000, no one knew what caused the disease or how it spread and few recognized the danger it posed to the U.S. potato industry. By the mid-2000s, ZC had cost Texas potato farmers millions in lost revenue and the disease had spread to New Mexico, Colorado, and Nebraska, including some seed production areas. During this period the disease began to gain attention of producers outside of Texas. In 2011, when ZC was reported from the PNW, where nearly $60 \%$ of the entire U.S. potato crop is produced, it was more than clear that ZC was not going away and that it did indeed pose a threat to the U.S. potato industry. Fortunately, disease management programs have been developed that, when diligently followed, have significantly reduced the devastating losses such as those experienced by Texas growers in the mid-2000s and those in the PNW in 2011. However, these programs are heavily dependent on numerous insecticide applications and therefore, as currently practiced, are expensive and likely nonsustainable. Furthermore, because late-season insecticide applications have no measureable impact on disease incidence or crop quality at harvest, growers are often hesitant to apply insecticide applications the last week or two before harvest or vine-kill. When ZC was first detected in the United States, the obvious and most immediate goal was to develop management strategies that stopped the postflowering onset of disease that was devastating potato yields, crop quality and marketability. With current discoveries concerning late-season infections and continued disease development after vine kill and even in storage, it is clear that this previously unrecognized aspect of $\mathrm{ZC}$ must be given more attention.

There are several issues, relating to late-season infections and postharvest disease development that require additional research (Box 2). First, late-season infections are only a problem if a "large number" of bacteriliferous psyllids are present in the field at season's end. If they are present, there is potential for serious losses during storage but what exactly constitutes a "large number" of infectious psyllids? Data from psyllid surveys conducted during the last several years have shown that the percentage of Lso positive psyllids collected on sticky traps is typically less than $3 \%$. However, sticky traps are notoriously unreliable in estimating actual pest

\section{BOX 2}

Priority needs for future research on late-season infections

- Improved late-season, pre- and post-harvest management practices

- Better information on how climatic and environmental conditions impact development and activity of psyllid populations

- Improved methods for pathogen and vector detection, monitoring, and quantification

- Improved understanding of how zebra chip develops after vine kill and in storage

- Development of a disease forecasting model and an action threshold specifically for late-season psyllid infestations and infections

- Grower education and training programs that focus on importance of late-season infections and best management practices populations so there is an urgent need to develop better, more precise, psyllid monitoring techniques and programs. Likewise, even when infectious psyllids are present, does the number warrant another insecticide application? Only when growers have a valid estimation of psyllid pressure will they be able to make informed management decisions. Butler and Trumble (2012) developed an action threshold for potato psyllids and ZC management, in which tolerance for psyllids increased as the season progressed. However, at the time the model was developed, none of the information about the potential for continued disease development after vine-kill or during storage was available, so a risk assessment model coupled with an action threshold that takes this information into account is needed. Such a model would be useful, not only for making decisions concerning insecticide applications, but also in determining the risk associated with leaving tubers in warm soils for extended periods following vine-kill.

When late-season infections occur less than one week before harvest, no symptoms of ZC are present in tubers at harvest and Lso is not detectable. Such tubers could easily, but incorrectly, be certified as "disease free." However, when these infected, but asymptomatic, tubers are placed into storage, Lso titer continues to increase during the curing period resulting in reduced tuber quality, an unacceptable outcome regardless of the intended end use of the crop. This situation highlights the need for more sensitive Lso detection methods in combination with statistically sound sampling methods that provide a verifiable degree of confidence that a particular lot of tubers does not exceed a given disease threshold. Based on results of a recent study by Rashed et al. (2014a), multiple samplings during the storage period likely will be required to provide the desired degree of confidence. Furthermore, even though the optimal temperature regimes for individual potato cultivars during storage are well established, additional research on temperature manipulation and its potential application to reduce rate of Lso increase in infected tubers is warranted. It is possible that a slight change in storage temperature profile could prevent or delay increase in Lso titer and help maintain tuber quality at an acceptable level.

\section{LITERATURE CITED}

Buchman, J. L., Sengoda, V. G., and Munyaneza, J. E. 2011. Vector transmission efficiency of Liberibacter by Bactericera cockerelli (Hemiptera: Triozidae) in zebra chip potato disease: Effects of psyllid life stage and inoculation access period. J. Econ. Entomol. 104:1486-1495.

Butler, C. D., and Trumble, J. T. 2012. Spatial dispersion and binomial sequential sampling for the potato psyllid (Hemiptera: Triozidae) on potato. Pest Manag. Sci. 68:865-869.

Crosslin, J. M., Hamm, P. B., Eggers, J. E., Rondon, S. I., Sengoda, V. G., and Munyaneza, J. E. 2012a. First report of zebra chip disease and 'Candidatus Liberibacter solancearum' on potatoes in Oregon and Washington State. Plant Dis. 96:452.

Crosslin, J. M., Olsen, N., and Nolte, P. 2012b. First report of zebra chip disease and 'Candidatus Liberibacter solancearum' on potatoes in Idaho. Plant Dis. 96:453.

Davis, T. S., Horton, D. R., Munyaneza, J. E., and Landolt, P. L. 2012. Experimental infection of plants with an herbivore associated bacterial endosymbiont influences host selection behavior. PLoS One 7:e49330.

Draxler, R. R., and Hess, G. D. 1998. An overview of HYSPLIT_4 modeling for trajectories, dispersion, and deposition. Aust. Meteorol. Mag. 47:295-308.

Gao, F., Jifon, J., Yang, X., and Liu, T.-X. 2009. Zebra chip disease incidence on potato is influenced by timing of potato psyllid infestation, but not by the host plant on which they were reared. Insect Sci. 16:399-408.

Glick, P. A. 1939. The distribution of insects, spiders, and mites in the air. USDA Tech. Bull. No. 673.

Goolsby, J. A., Adamczyk, J., Bextine, B., Lin, D., Munyaneza, J. E., and Bester, G. 2007. Development of an IPM program for management of the potato psyllid to reduce incidence of zebra chip disorder in potatoes. Subtropic Plant Sci. 59:85-94.

Goolsby, J. A., Adamczyk, J. J., Crosslin, J. M. Toxclair, N. N., Anciso, J. R., Bester, G. G., Bradshaw, J. D., Bynum, E. D., Carpio, L. A., Henne, D. C., Joshi, A., Munyaneza, J. E., Porter, P., Sloderbeck, P. E., Supak, J. R., Rush, C. M., Willet, F. J., Zachmann, B. J., and Zens, B. A. 2012. Seasonal population dynamics of potato psyllid (Hemiptera: Triozidae) and its 
associated pathogen 'Candidatus Liberibacter solancearum' in potatoes in the southern great plains of North America. J. Econ. Entomol. 105:1268-1276.

Hamm, P. B., Rondon, S. I., Crosslin, J. M., and Munyaneza, J. E. 2011. A new threat in the Columbia Basin of Oregon and Washington: Zebra Chip. Pages 1-5 in: Proceedings of the 11th Annual Zebra Chip Reporting Session. F. Workneh and C. M. Rush, eds. San Antonio, TX.

Hansen, A. K., Trumble, J. T., Stouthamer, R., and Paine, T. D. 2008. A new huanglongbing species, 'Candidatus Liberibacter psyllaurous,' found to infect tomato and potato, is vectored by psyllid Bactericera cockerelli (Sulc). Appl. Environ. Microbiol. 74:5862-5865.

Henne, D., Bradshaw, J., Whipple, S., Carpio, L., Schuster, G., Porter, P., Barrett, S., Whillet, J., Mathews, J. M., and Deroo, K., Seger, P., Crosslin, J., and Hamlin, L. 2013. Overview of the 2012-2013 potato psyllid area-wide monitoring program. Pages 1-5 in: Proceedings of the 13th Annual SCRI Zebra Chip Reporting Session. F. Workneh and C. M. Rush, eds. San Antonio, TX.

Henne, D. C., Paetzold, L., Workneh, F., and Rush, C. M. 2010. Evaluation of potato psyllid cold tolerance, overwintering survival, sticky trap sampling, and effects of LSO on potato psyllid alternate host plants. Pages 149-153 in: Proceedings of the 10th Annual Zebra Chip Reporting Session. F. Workneh and C. M. Rush, eds. Dallas, TX.

Liefting, L. W., Sutherland, P. W., Ward, L. I., Paice, K. L., Weir, B. S., and Clover, G. R. G. 2009a. A new 'Candidatus Liberibacter' species associated with diseases of solanaceous crops. Plant Dis. 93:208-214.

Liefting, L. W., Weir, B. S., Pennycook, S. R., and Clover, G. R. G. 2009 b. 'Candidatus Liberibacter solanacearum', a Liberibacter associated with plants in the family Solanaceae. Int. J. Syst. Evol. Microbiol. 59:2274-2276.

Lin, H., and Gudmestad, N. C. 2013. Aspects of pathogen genomics, diversity, epidemiology, vector dynamics and disease management for a newly emerged disease of potato: Zebra chip. Phytopathology 103:524-537.

List, G. M. 1939. The effect of temperature upon egg deposition, egg hatch and nymphal development of Paratrioza cockerelli (Sulc). J. Econ. Entomol. 32:30-36.

Liu, D., Trumble, J. T., and Stouthamer, R. 2006. Genetic differentiation between eastern populations and recent introductions of potato psyllids (Bactericera cockerelli) into Western North America. Entomol. Exp. Appl. 118:177-183.

Munyaneza, J. E. 2012. Zebra chip disease of potato: Biology, epidemiology and management. Am. J. Potato Res. 89:329-350.

Munyaneza, J. E., Crosslin, J. M., and Buckmann, J. L. 2009. Seasonal occurrence and abundance of the potato psyllid, Bactericera cockerelli, in south central Washington. Am. J. Potato Res. 86:513-518.

Munyaneza, J. E., Crosslin, J. M., and Upton, J. E. 2007a. Association of Bactericera cockerelli (Homoptera: Psyllidae) with "zebra chip", a new potato disease in southwestern United States and Mexico. J. Econ. Entomol. 100:656-663.

Munyaneza, J. E., Goolsby, J. A., Crosslin, J. M., and Upton, J. E. 2007b. Further evidence that zebra chip potato disease in the Lower Rio Grande Valley of Texas is associated with Bactericera cockerelli. Subtrop. Plant Sci. 59:30-37.

Murphy, A. F., Rondon, S. I., and Jensen, A. S. 2013. First report of potato psyllids, Bactericera cockerelli, overwintering in the Pacific Northwest. Am. J. Potato Res. 90:294-296.

Nachappa, P., Shapiro, A. A., and Tamborindeguy, C. 2012. Effect of 'Candidatus Liberibacter solanacearum' on fitness of its host vector, Bactericera cockerelli (Hemiptera:Triozidae), on tomato. Phytopathology 102:41-46.

Navarre, D. A., Shakya, R., Holden, J., and Crosslin, J. M. 2009. LC-MS analysis of phenolic compounds in tubers showing zebra chip symptoms. Am. J. Potato Res. 86:88-95.

Paetzold, L., Rashed, A., Workneh, F., and Rush, C. M. 2014. Temporal and spatial variations of psyllid haplotypes occurring in indigenous vegetation in Texas. Pages 63-67 in: Proceedings of the 14th Annual Zebra Chip Reporting Session. F. Workneh and C. M. Rush, eds. Portland, OR.

Pletsch, D. J. 1947. The potato psyllid Paratrioza cockerelli (Sulc), its biology and control. Mont. Agr. Exp. Stn. Bull. 446:95.

Rashed, A., Nash, D., Paetzold, L., Workneh, F., and Rush, C. M. 2012. Transmission efficiency of 'Candidatus Liberibacter solanacearum' and potato zebra chip disease progress in relation to pathogen titer, vector numbers, and feeding sites. Phytopathology 102:1079-1085.

Rashed, A., Wallis, C. M., Paetzold, L., Woodell, L., Olsen, N., Workneh, F., Rashidi, M., Wenninger, E. J., and Rush, C. M. 2014a. 'Candidatus Liberibacter solanacearum' development in Russet Norkotah under commercial storage conditions. Pages 13-17 in: Proceedings of the 14th Annual Zebra Chip Reporting Session. F. Workneh and C. M. Rush, eds. Portland, OR.

Rashed, A., Wallis, C. M., Paetzold, L., Workneh, F., and Rush, C. M. 2013. Zebra chip disease and potato biochemistry: Tuber physiological changes in response to 'Candidatus Liberibacter solanacearum' infection over time. Phytopathology 103:419-426.

Rashed, A., Workneh, F., Gray, J., Paetzold, L., and Rush, C. M. 2014b. Zebra chip disease development in relation to plant age and time of 'Candidatus Liberibacter solanacearum' infection. Plant Dis. 98:24-31.
Rashed, A., Workneh, F., Paetzold, L., and Rush, C. M. 2015. Emergence of 'Candidatus Liberibacter solanacearum'-infected seed potatoes in relation to the time of infection. Plant Dis. 99:274-280.

Romney, V. E. 1939. Breeding areas of the tomato psyllid, Paratrioza cockerelli (Sulc). J. Econ. Entomol. 32:150-151.

Rosson, P. 2006. Economic impacts of Zebra Chip on the Texas potato industry. Internal economic analysis solicited by Frito Lay and produced by Texas AgriLife Research Economists, Center for North American Studies, Texas A\&M University, College Station, TX.

Rush, C. M., Workneh, F., Paetzold, L., Olsen, N., Henne, D., and Rashed, A. 2014. Impact of vine-kill on Lso and zebra chip symptom development in tubers following late season psyllid infestations. Pages 18-22 in: Proceedings of the 14th Annual Zebra Chip Reporting Session. F. Workneh and C. M. Rush, eds. Portland, OR.

Rush, C. M., Workneh, F., Paetzold, L., and Rashed, A. 2013. Impact of initial psyllid population density on pathogen and disease dynamics. Pages 20-23 in: Proceedings of the 13th Annual SCRI Zebra Chip Reporting Session. F. Workneh and C. M. Rush, eds. San Antonio, TX.

Sandanayaka, W. R. M., Moreno, A., Tooman, L. K., Page-Weir, N. E. M., and Fereres, A. 2014. Stylet penetration activities linked to the acquisition and inoculation of 'Candidatus Liberibacter solanacearum' by its vector tomato potato psyllid. Entomol. Exp. Appl. 151:170-181.

Secor, G. A., Rivera, V. V., Abad, J. A., Lee, I. M., Clover, G. R. G., Liefting, L. W., Li, X., and De Boer, S. H. 2009. Association of 'Candidatus Liberibacter solanacearum' with zebra chip disease of potato established by graft and psyllid transmission, electron microscopy, and PCR. Plant Dis. 93: 574-583.

Sengoda, V. G., Buchman, J. L., Henne, D. C., Pappu, H. R., and Munyaneza, J. E. 2013. 'Candidatus Liberibacter solanacearum' copies over time in the potato psyllid Bactericera cockerelli (Hemiptera: Triozidae), following acquisition from infected potato and tomato plants. J. Econ. Entomol. 106:1964-1972.

Snyder, W. C., Thomas, H. E., and Fairchild, S. J. 1946. Spindling or hair sprout of potato. Phytopathology 36:897-904.

Swisher, K. D., Munyaneza, J. E., and Crosslin, J. M. 2012. High resolution melting analysis of the cytochrome I gene identifies three haplotypes of the potato psyllid in the United States. Environ. Entomol. 41:1019-1028.

Wallis, C. M., Chen, J., and Civerolo, E. L. 2012. Zebra chip-diseased potato tubers are characterized by increased levels of host phenolics, amino acids, and defense-related proteins. Physiol. Mol. Plant Pathol. 78:66-72.

Wallis, C. M., Rashed, A., Chen, J., Paetzold, L., Workneh, F., and Rush, C. M. 2015. Effects of potato-psyllid-vectored 'Candidatus Liberibacter solanacearum' infection on potato leaf and stem physiology. Phytopathology 105:189-198.

Wallis, R. L. 1946. Seasonal occurrence of potato psyllid in the North Platte Valley. J. Econ. Entomol. 39:689-694.

Wallis, R. L. 1955. Ecological studies on the potato psyllid as a pest of potatoes. USDA Tech. Bull. 1107.

Wen, A., Mallik, I., Alvarado, V. Y., Pasche, J. S., Wang, X., Li, W., Levy, L., Lin, H., Scholthof, H. B., Mirkov, T. E., Rush, C. M., and Gudmestad, N. C. 2009. Detection, distribution, and genetic variability of 'Candidatus Liberibacter' species associated with zebra chip complex disease 1 of potato in North America. Plant Dis. 93:1102-1115.

Whipple, S., Bradshaw, J. D., and Harveson, B. 2012. Cold tolerance in potato psyllids. Pages 191-193 in: Proceedings of the 12th Annual Zebra Chip Reporting Session. F. Workneh, A. Rashed, and C. M. Rush, eds. San Antonio, TX.

Williams, R. D., and Hoagland, R. E. 1982. The effects of naturally occurring phenolic compounds on seed germination. Weed Sci. 30:206-212.

Workneh, F., Goolsby, J. A., Henne, D. C., Rashed, A., Paetzold, L., Hamm, P. B., Rondon, S. I., and Rush, C. M. 2011a. Exploratory assessments of weather variables in relation to psyllid/ZC prevalence. Pages 7-11 in: Proceedings of the 11th Annual Zebra Chip Reporting Session. F. Workneh, A. Rashed, and C. M. Rush, eds. San Antonio, TX.

Workneh, F., Henne, D. C., Childers, A. C., Paetzold, L., and Rush, C. M. 2012. Assessments of the edge effect in intensity of potato zebra chip disease. Plant Dis. 96:943-947.

Workneh, F., Henne, D. C., Goolsby, J. A., Crosslin, J. M., Whipple, S. D., Bradshaw, J. D., Rashed, A., Paetzold, L., Harveson, R. M., and Rush, C. M. 2013. Characterization of management and environmental factors associated with regional variations in potato zebra chip occurrence. Phytopathology 103:1235-1242.

Workneh, F., Henne, D. C., Paetzold, L., and Rush, C. M. 2011b. Effect of temperature on potato psyllid reproduction and Liberibacter titer level in tubers. (Abstr.) Phytopathology 101(suppl.):S194.

Workneh, F., Henne, D. C., Paetzold, L., Silva, A., and Warfield, B., Bradshaw, J. D., and Rush, C. M. 2014. Overview of the 2013-2014 potato psyllid areawide monitoring program. Pages 1-5 in: Proceedings of the 14th Annual Zebra Chip Reporting Session. F. Workneh and C. M. Rush, eds. Portland, OR.

Yang, X. B., Malik, N. S. A., Perez, J. L., and Liu, T. X. 2011. Impact of potato psyllid (Hemiptera: Triozidae) feeding on free amino acid composition in potato. Insect Sci. 18:663-670. 